\title{
Employee Competency Management Initiative: A Literature Review
}

\author{
Sesugh, Esther Hephzibah PhD. \\ Department of Management, Faculty of Management Sciences \\ Rivers State University, Port Harcourt, Nigeria
}

\begin{abstract}
This paper discussed the concept of employee competency management initiatives. The paper highlighted particularly on three competency management initiatives - employee training, workplace mentoring and coaching. The paper is theoretical and as such draws its significance from its focus on the need for flexible and fluid employee competency initiatives given the changing dynamics and features of the work and business environment. This position is also hinged on the observed challenges of change and the imperatives for organizational learning and management re-orientation in line with the shifts in the market and the global community. The study concludes that the adoption and application of competency initiatives should begin with the specific needs of the organization as well as the specification of its goals. The design and features of competency management initiatives such as employee training, workplace mentoring and coaching, premised on the specifications of the organizations own particular experiences and expectations will offer more focus and will be more effective in addressing the organizations own unique or particular challenges and problems
\end{abstract}

\section{Keywords: Employee Training, Mentoring, Coaching, Competency, Initiatives, Organizational Learning}

\section{Introduction}

Organizations' ability to recruit and retain capable employees has become a major challenge in this rapidly changing business environment, especially given the fierce competition among firms to acquire same scarce workforce that are perceive to be of high potentials. Despite this fact capable employee still need to be provided with training and development activities so as to increase their skills and promote efficiency at the workplace. This process increases individual's efficiency executing distinct task assigned keeping in mind the strategic objectives and goals of the firm. These are contained in and form the organizations HR or employee competency initiatives and increase firm's probability of achieving organizational performance (Brown \& Sitzmann, 2011; Bartram, 2004). Furthermore, thus contributes to a continuous learning process of the organization and increase effectiveness in both long and short run.

Also, due to the ever changing and dynamic nature of the business environment, employees need to acquire new skills that can be used in new fields and in addressing emerging social and organizational challenges. Thus, there is the need for employee competency management initiatives that are flexible and fluid, and as such enhance employees analytical and problem-solving skills such that enable them to solve real time challenges in a proactive manner. And this result in waste and cost reduction that helps firms adapts to change (Rao, 2000).

Insofar, as training, mentoring and coaching are considered as essential tools and initiatives for developing capable employees. Hence, for firms to take advantage of these capable abilities it is critical for firms to align strategic focus and goals to its training activities. When training, mentoring and coaching are aligned with firm corporate level and overall business strategies, it enables employees to have in-depth insight as to the overall expectation of their tasks and jobs and its impact on the performance and sustainability of the organization (Bartram, 2004; Thomson \&Strickland, 2004).

This paper as such discussed employee competency management initiatives from the light of their appropriability in addressing the unique and ever-changing problems of employee development and role performance within organizations today. This is as studies indicate that given the advent of globalization and 
the merging of boundaries and markets, most skills have become obsolete with new knowledge capacities and competencies emerging from the newly created and fused social norms, cultures and values that now define most contexts and economies.

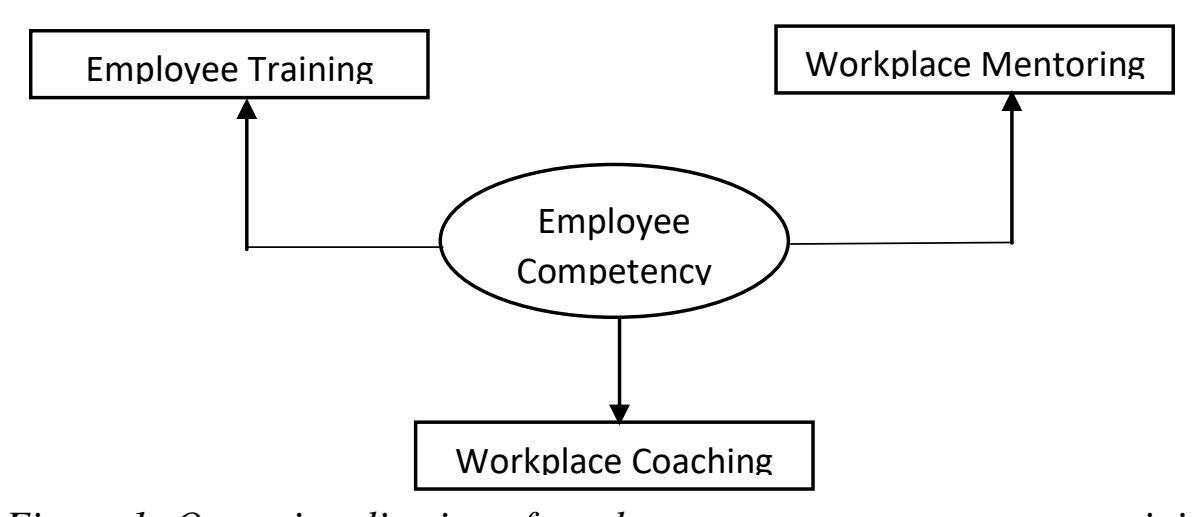

Figure 1: Operationalization of employee competency management initiatives

\section{Literature Review \\ Theoretical Foundation \\ Resource-Based Theory}

The resource-based theory is concerned with the idea that a firm's internal resources can become a direct source of sustained competitive advantage for the organization. This is distinct from traditional notions of competitive advantage popularized first by Porter (1985) which stressed competitive advantage was attained for the firm through external means such as products, location or customer base. Sveiby (2000) emphasized on the distinction that while traditional views of competitive advantage, such as Porter's, are product based, the resource-based view is knowledge-based, thus implying a focus on the development and enhancement of the competencies of the human resources or employees. The notion that a firm's human resources could be a source of advantage and competitive edge dates to 1984 (Fahy, 2000).

The resource-based theory offers a more dynamic approach towards understanding the need for employee competency as it emphasizes on the employees as the key facets and assets which can be utilized and enhanced to address the organizations effectiveness, competitiveness and performance issues. The theory offers several implications with regards to the need for employee competency with regards to the firm's goals and objectives. These are stated as follows:

i. The firm must seek for ways or initiatives that ensure that it has capable and committed employees. These can focus on the development or design of programs and functions aimed at enhancing employee skills and knowledge or strengthening employee relationships and collaboration.

ii. The firm must emphasize and also commit to the strategic focus and importance of human resources or employee competency management and development as a path to the success of the business.

iii. Employee or human resource competency development activities must be managed by specialists or consultants.

iv. Employee competency management is integrated into the business strategy of the organization.

In addition to the above, a firm's employees must also possess certain characteristics. Wright and McMahan (1992) claim that in order for a firm's internal resources (human or otherwise) to provide the required competitive edge or advantage, four criteria must be attributable to the given resource: (a) the resource must add value to the firm, (b) the resource must be unique or rare among current and potential competitors, (c) the resource must be impossible to imitate perfectly, and (d) the resource cannot be substituted with another similarly functioning resource by competing firms. Having the organization in place' means having capable management in the organization is necessary. It also means more generally that the organization's systems, procedures, policies, structure and other internal elements must be organized and aligned in ways which support internal resources being able to be used strategically. Chew et. al. (2008) call this the process of organizing resources into capabilities. Resources themselves, the authors claim, only have the potential to create competitiveness but need to become organizational capabilities before they can add value. 


\section{Competency}

The term competency was probably first introduced to psychology literature in 1973 when David McClelland argued in his article 'Testing for competence rather than for intelligence' that traditional tests of academic aptitude and knowledge content in fact predicted neither job performance nor success in life. Thus, the quest for theory and tools that could reliably predict effectiveness in the workplace began (McClelland, 1973). Boyatzis (1982) is considered one of the first to put together a comprehensive data that had been collected in the USA using the McBer \& Company 'Job Competence Assessment' method. Since then, competency has become a significant factor in HR development practices (Simpson, 2002). The word competency comes from a Latin word meaning "suitable" (Bueno and Tubbs, 2004). Boyatzis (1982) defines a competency as "an underlying characteristic of a person which results in effective and superior performance in a job.

According to Boyatzis (1982) competency represents ability. An individual's set of competencies reflect their capability or what they can do. A job competency may be a motive, trait, skill, aspect of one's selfimage or social role, or a body of knowledge that an individual use, and the existence and possession of these characteristics may or may not be known to the individual. Similarly, Mitrani et al. (1992) state that competencies could be motives, traits, self-concepts, attitudes or values, content knowledge, or cognitive or behavioural skills. A competency is an individual characteristic that can be measured or counted reliably and that can be shown to differentiate significantly between superior and average performers, or between effective and ineffective performers. Meanwhile, competency can be described as a set of behaviour patterns that an incumbent need to bring to a position in order to perform its tasks and functions in the delivery of desired results or outcomes (Bartram, et. al, 2002; Woodruffe, 1992).

Rossilah (2008) stated that competency or efficiency was referred to as a set of characteristics of knowledge, skills, attitudes, intellect and view of one's own interests to carry out their duties efficiently and effectively. McClelland (1998) further defined competency as basic personal characteristic that is a determining factor for acting successfully in a job or situation. It is important for an organization to ensure that employees have the knowledge, skills and attitude in accordance with the organization goals, objectives and values.

Spencer and Spencer (1993) viewed competency as an underlying characteristic of an individual that is causally related to criterion-referenced effective and/or superior performance in a job or situation. They identified five types of competency characteristics consisting of motives, traits, self-concept, knowledge and skills. First, motives are the things that an individual consistently thinks about or wants that stimulate action. Motives drive, direct and select behaviour toward certain actions or goals and away from others. Second, traits are physical characteristics and consistent responses to situations or information. Third, self-concept is an individual's attitudes, values or self-image. Fourth, knowledge is the information that an individual has in specific content areas. Finally, skill is the ability to perform a certain physical or mental task. Knowledge and skill competencies tend to be visible and relatively surface characteristics, whereas self-concept, traits and motive competencies are more hidden, deeper and central to personality. Surface knowledge and skill competencies are relatively easy to develop and training is the most cost-effective way to secure those employee abilities (Spencer and Spencer, 1993).

In other words, visible competencies such as knowledge and skills may be somewhat technical competencies basically required by the job, whereas hidden competencies such as self-concept, traits and motives are behavioural competencies that drive an individual's performance in the job. Boyatzis (1982) states that motive and trait competencies have the most direct impact on self-concept and also have an impact on skill. The United Nations Industrial Development Organization (UNIDO, 2002) defines competency as a set of skills, related knowledge and attributes that allow an individual to perform a task or activity within a specific function or job. If an individual possesses these three elements of competency, they can effectively perform duties as required by the specific job.

From the wide range of related literature, the definition of competency can be summarized as an underlying characteristic of an individual that is causally related to criterion-referenced effective and/or superior performance in a job or situation. Job competency is a set of behaviour patterns that a job incumbent needs to bring to a position in order to perform its tasks and functions with competence. A job competency can be 
a motive, trait, skill, self-concept, body of knowledge or an attribute that allows an individual to perform a task or activity within a specific function or job.

Skill and knowledge are surface or technical competencies that can be developed easily by training. On the other hand, motives, traits and self-concept are hidden or behavioural competencies that are difficult to develop. Traditionally, it is essential for an individual to possess the required technical competencies at a threshold level in order to adequately perform their job. However, the changing environment and diverse workforce has resulted in behavioural competencies becoming crucial as the greatest determinants of an individual's performance. Thus, in order to be effective in a job, individuals need to possess or acquire both technical and behavioural competencies and use these together in performing their tasks.

Mitrani et al. (1992) mention the need for competency and predict that organizations of the future will be built around people. They add that there will be less emphasis on jobs as the building blocks of an organization; instead increased attention will be focused on employee competence. If we are using people as the building blocks of an organization, then competence or what they bring to the job becomes crucial. The competency approach to selection and assessment is based on classifying, identifying, and measuring individual differences for particular work-related constructs that are relevant to successful job performance (Bartram, 2004).

Cummings and Worley (2001) similarly state that organizational changes frequently demand new knowledge, skills and behaviour from employees. They argue that in many cases changes could not be implemented unless employees gained new competencies. They also suggest that change agents are needed to provide multiple learning opportunities, such as traditional training programs, on-the-job counselling and coaching, and experiential simulations, covering both technical and social skills, and that it must be ensured that such learning occurs.

\section{Employee Competency}

Employee competency refers to the abilities or capabilities of particular individuals who identify and are recognized as forming the workforce of the organization (Bartram, 2004). The Society for Human Resource Management (2003) has indicated that competencies have become integral in the field of HRM. The Society cite supporting evidence showing that in the last thirty years the competency approach has emerged from being a specialized and narrow application to being a leading technique for diagnosing, framing and improving most aspects of HRM. According to the Society, a new competency model was necessary because the business world was changing at an unprecedented rate. These changes require HR professionals to add significant value and to do so quickly. Moreover, since HRM activities directly impact company ability to compete, competency models need to be continually researched and updated (Society for Human Resource Management, 2003).

Thomson and Strickland (2004) also place building core competencies and competitive capabilities as a key component of building a capable organization. They state that building core competencies and competitive capabilities will enable good strategy execution and that maintenance of a competence/capability portfolio, that is updated as strategy and external conditions change, will guarantee that an organization is capable of effective strategy execution. From the literature cited above it can be summarized that, during the last thirty years, competency has become a key factor in HRM in terms of building a capable organization.

This is because academic or knowledge content alone is insufficient for an individual to be successful in their job. Rather, desired characteristics or behaviour are meaningful in ensuring that an individual is effective in performing their tasks according to the job demands. People capital has become a valuable asset to both current and future organizations. Therefore, competence needs to be focused and, if we are using people as the building blocks of the organization, then their competence becomes crucial.

Competent employees are the main resource of any organization in acquiring a competitive advantage. Land, buildings or materials do not yield company productivity, rather, it is 'people capital' that runs a business and produces value from existing resources. Hay Group (2004) point out that an organization's best source of competitive advantage lies with its employees. Strategies, business models, products and services can all be copied by competitors, but talented and competent employees represent a sustainable source of differentiation. 
The demand for effective and competent employees continuously increases in both public and private organizations because a dynamic global marketplace and increasing foreign competition has compelled organizations to become more effective and flexible in response to the rapidly changing environment. As a result, this is a suitable time to assess human resource management (HRM) practices that can augment organizational performance in public sector organizations (Gould-Williams, 2003).

Table 1: Conceptualizations of employee competency.

\begin{tabular}{|c|c|c|}
\hline Authors & Definitions & Measurement \\
\hline McClelland (1998) & $\begin{array}{l}\text { Competency as basic personal characteristic } \\
\text { that is a determining factor for acting } \\
\text { successfully in a job or situation. }\end{array}$ & $\begin{aligned} \text { i. } & \text { Ability } \\
\text { ii. } & \text { Attitude } \\
\text { iii. } & \text { Knowledge }\end{aligned}$ \\
\hline Rao (2000) & $\begin{array}{l}\text { Competency refers to the workers level of } \\
\text { effectiveness in addressing both task and social } \\
\text { expectations, particularly those that relate to } \\
\text { the organization. }\end{array}$ & $\begin{aligned} & \text { i. } \text { Knowledge } \\
& \text { ii. } \text { Trait } \\
& \text { iii. } \text { Skill } \\
& \text { iv. } \text { Self-concept } \\
& \text { v. } \text { Motives } \\
&\end{aligned}$ \\
\hline Boyatzis (2008) & $\begin{array}{l}\text { Competency describes the individual's ability } \\
\text { and capability to perform and carry out a given } \\
\text { task or expectation }\end{array}$ & $\begin{aligned} \text { i. } & \text { Capability } \\
\text { ii. } & \text { Ability } \\
\text { iii. } & \text { Capacity }\end{aligned}$ \\
\hline Rossilah (2008) & $\begin{array}{l}\text { Competency } \text { describes the individual's } \\
\text { functionality within a particular frame or } \\
\text { context }\end{array}$ & $\begin{aligned} \text { i. } & \text { Knowledge } \\
\text { ii. } & \text { Intellect } \\
\text { iii. } & \text { Attitudes } \\
\text { iv. } & \text { Skills }\end{aligned}$ \\
\hline
\end{tabular}

Source: Author

\section{Employee Competency Management Initiatives}

The performance and success of any organizations depends on its skilled employees and how efficient the organization can tap into that resource and make effective use of it. Despite this opportunity the dynamic nature of the business environment makes this process a complex one (Thomson and Strickland, 2004). Therefore, organizations should adapt strategic processes and initiatives to enhance the competencies its employees to adapt to this evolving environment both internally and externally. While a variety of employee competency management initiatives appear to dominate literature (Jimenez-Jimenez and Sanz-valle, 2011; Rao, 2000; Spencer and Spencer, 1993) this study streamlines its focus to three major features: (a) employee training, (b) workplace mentoring and (c) coaching.

Employee Training: Training modifies employee's behaviour, attitudes and values about their job and the organization as a whole. Employees' further gain requisite skills and this contributes to the performance of the organization (Brown \& Sitzman, 2011). Although training is significant to the development and performance of either the employee or the organization achieving effective training process is hindered by many factors especially a non-friendly environment. Therefore, firms need to create an enabling environment and this is critical to organizational learning (Jimenez-Jimenez \& Sanz-valle, 2011).

Rao (2000) emphasized that in order for the employee to obtain all the needed competencies, organizations must develop a proper training program. There are five types of competency characteristics: Motives, traits, self-concept, knowledge and skills. All these characteristics were linked with superior performance in doing a job (Rao, 2000). Brown and Sitzman (2011) recommended that competent employees in a highperformance organization possess necessary skills, competency and ability to express their ideas. They will excel and perform to the fullest if they are offered favourable environment. The performance of the entire organization depends on its employee competencies. 


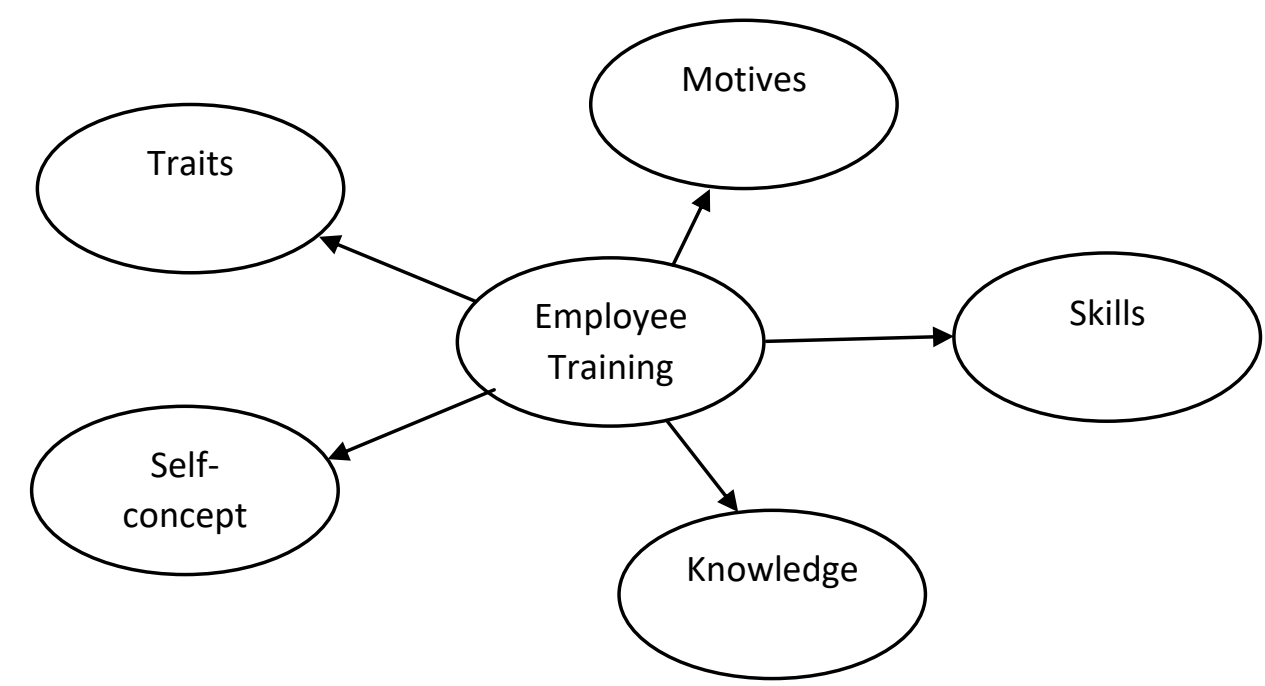

Figure 2: Employee competency characteristics (Rao, 2000).

Employee competencies (EC) can be improved through effective training programs designed to subsequently enhance the employee overall performance. By gaining suitable knowledge, skills and attitude through training they can perform their current job more effectively and also prepare for future job (Rodrigues and Chincholkar, 2005). Rao (2000) revealed that employee competency has mediating effect between human resource management function and service quality among workers.

Training is also one of the functions in human resource development while employee performance is one of the indicators in service quality elements. The improvement in skills and knowledge will lead to superior service performance that may affect creativity, operational effectiveness and high-quality service delivery among frontline employees in the service industry. Rao (2000) stated that competencies are seen as the ultimate mediator between training interventions and performance of the job.

Workplace Mentoring: Mentoring describes the relationship between two or more individuals which entails a learning and supportive interaction between the identified parties, with one considered as offering more from their wealth of experience or knowledge. Mentoring is frequently used in companies as a systemic solution to increase the performance of employees (Lisa, 2011). Mentoring is essential in the 21st century workplace where there changing business climate, which involves an expected large exodus of executives, increase in the use of technology, and global competition.

A large proportion of the executives are between the age of 46 to 64 years and more than $50 \%$ are bound to retire in a few years (Callanan \& Greenhaus, 2008). When these people retire, they will take with them knowledge that is needed by organizations to continue to grow, be profitable, and sustain employee performance levels. This is because the senior leaders who believed in the organization vision, knowledge, external and internal personal networks, skills and historical context will be lost when these individuals leave the organization (Peterson and Hicks, 2010). Therefore, the need to transfer this knowledge to the next generation of leaders, managers and other is important to sustain employee performance. In this regard, mentoring is needed to address the great loss of knowledge and lost performance that is anticipated to occur.

The term mentoring is usually confused with coaching, although the terms are distinctly different their definitions are based on the specific activity that is taking place and the role of the players (Brockbank \&McGill, 2006). Coaching is a term is used to describe a variety of activities from sports coaching, life coaching, leadership and executive coaching to team coaching in organisations (Thomas, 2011). Coaching is largely used when a person or organisation is working towards some change in growth and development, and improving performance (Ritchie \& Genoni, 2012). Whereas, mentoring is often associated with induction, career and personal development and personal change, even within the context of the organization (Cameron, 2007).

Mentoring focuses on helping an individual acquire the skills necessary to do their job and possibly further their career (Zachary, 2012). The mentee sets the agenda based on their own development needs, and the 
mentor provides insight and guidance to help them achieve their desired goals (Thomas, 2011). A mentee is usually someone with little or no experience of either work in general or the type of work they are going to be doing in particular. Conversely, the mentor should be someone who has plenty of work experience in general and knowledge of how your business operates in particular (Ready, Conger, Hill and Stecker, 2010).

A well-structured mentoring programme can benefit the organization in a number of ways by broadening the staff's insight, increasing productivity, improving the mentee's performance to engage the employees that can lead to better retention and performance levels (Orth, Wilkinson \& Benfari, 2009). This gives the mentor a sense of responsibility and the satisfaction of passing on their knowledge and builds relationships between the employees by encouraging the exchange of information and experience (Thomas, 2011). The benefits of the mentor to the mentees involves helping the mentees integrate better, increase their confidence, give the mentee a stronger awareness of the organization culture, allow the mentee to acknowledge their strengths and weaknesses, which can in turn lead to faster learning and improved employee performance (Ritchie \& Genoni, 2012).

Workplace Coaching: An effective coaching program can be of an immense assistance to help enhance the competency and as such productivity as well, engagement of staff in an organization. Gadot (2012) points out that the relationship existing between performance and leadership is both indirect and direct, this is why it is important for employers to develop their members of staff by use of development programs. Jarvis (2014) explains that different factors are responsible for increased use of coaching by different organizations today. Many organisations work under time pressure and dealing with change is nowadays an everyday challenge. An employee ability to learn and also adapt has become an important skill in today's organization. Therefore, coaching is used in today's workplace to help employees regulate workplace changes.

Furthermore, most organisations are flatter, there are broader management roles and lower job security which also currently contribute to the need and the growth of coaching. This in turn means that newly skilled individuals want more responsibilities and require effective competency management; hence coaching can support these individuals in achieving these expectations or needs. It is also a focus on lifelong learning and learning throughout one's life time is becoming increasingly vital in today's society (Jowett, 2012). Coaching supports many learning steps which leads to more employees to learn compared to traditional learning methods. Organizations can have different and diverse development needs and small firms have a disadvantage since very few employees have specific skills to meet such development needs. Coaching can in this case offer a good approach for development, which can be focused on the individualized, just-in-time development.

Jarvis (2014) explains that there is an increasing trend in today's organisations of individual learning and development in recognizing developmental competency needs of the employees, help in personal problem solving and planning of activities to be undertaken by the employee. Further, employees demand for different types of training and people are more motivated and learn best when the training is connected and relevant to their job. Research has found that employee's job performance is a function of their ability, their motivation to work, and their chance to organize their ideas, knowledge and abilities in an effective way; all of which boil down to their evidence of competency on the job. Coaching can help in enhancing an employee performance as it provides the employee with a chance to increase their skills and motivation which eventually leads to an overall positive impact on the employee job performance.

Coaching as used in the workplace is a recent development. Apprenticeships and other forms of individualized coaching have been in existence for decades however the earliest form of coaching that has been used in the workplaces is developmental counselling (Flory, 2015). Joan (2016) points out that from 1940 to 1979 , consultants were the ones performing organizational coaching. Coaches during this time were mainly organization development (OD) professionals and psychologists whose main focus was OD issues. However, the coaching field has experienced a growth spurt has over time come to offer relevance and considerations for the various changes in workplace relationships today.

\section{Conclusion}


Employee competency management initiatives offers a position on the development and channelling of employee capabilities, knowledge, motives and skillsets. As such, the study identifies employee competency management as an imperative in driving the workforce of the organization and in ensuring that its human resources values and orientations are in line with those of the organization, and as such, enhancing the cohesiveness and collaboration between units or workers within the organization. The study concludes that the adoption and application of competency initiatives should begin with the specific needs of the organization as well as the specification of its goals. The design and features of competency management initiatives such as employee training, workplace mentoring and coaching, premised on the specifications of the organizations own particular experiences and expectations will offer more focus and will be more effective in addressing the organizations own unique or particular challenges and problems.

\section{Recommendations}

The following recommendations are in line with the considerations of the conclusions of this paper:

i. The training of employees as a competency management initiative should be broadened to not only address the immediate needs and challenges of the organization but also its futuristic goals and change development targets.

ii. The mentoring of the employees as a competency management initiative should aim at aligning employee values and beliefs with those of the organization in a manner that drives their identification and openness towards supporting and adopting behavioural characteristics or traits that are useful and helpful to the organization.

iii. The coaching of employees as a competency management initiative, should focus on the development of the employee's strength and character especially in line with their self-concept and perceptions of self within the organization. This is critical to their confidence and performance on the job as well.

\section{References}

1. Bartram, D. (2004). Assessment in organizations. Applied psychology: An International Review, 53(2), 237-259.

2. Bartram, D., Robertson, I. T., \& Callinan, M. (2002). Introduction: A framework forexamining organizational effectiveness. In I.T. Robertson, M. Callinan, \& D. Bartram (Eds.), Organizational effectiveness: The role of psychology (1-12). Chichester, UK: Wiley.

3. Boyatziz, R. (2008). Competencies in the 21st centuries, Journal of Management Development, 27(1), 5-12.

4. Boyatzis, R. (1982). The competent manager: A model for effective performance. New York: John Wiley \& Sons.

5. Brockbank, A., \& McGill, I. (2006). Facilitating reflective learning through mentoring and coaching. London and Philadelphia: Kogan Page.

6. Brown K. \& Sitzmann T. (2011). APP handbook of industrial and organizational psychology, 2: Selecting \& developing, members for the organizations.

7. Bueno, C. \& Tubbs, S. (2004). Identifying global leadership competencies: An exploratory study. Journal of American Academy of Business, 5(1/2), 80-87.

8. Callanan, G., \& Greenhaus, J. (2008). The baby boom generation and career management: A call to action. Advances in Developing Human Resources 10(1), 70-85.

9. Chew, D.A.S., Yan, S., \& Cheah, C.Y.J. (2008). Core capability and competitive strategy for construction SMEs in China, Chinese Management Studies, 2(3), 203214.

10. Cummings, T., \& Worley, C. (2001). Organization development and change. Ohio: South Western College Publishing.

11. Fahy, J. (2000). The resource-based view of the firm: some stumbling blocks on the road to understanding sustainable competitive advantage, Journal of European Industrial Training, 24(2), 94 104.

12. Flory, U. (2015). Changing the mindset: the training myth and the need for word class performance. International Journal of Human Resource Management 12(4), 586-600.

13. Gadot, E. (2012). Leadership style, organizational politics, and employees' performance: An empirical examination of two competing models. Personnel Review, 36(5), 661-683. 
14. Gould-Williams, J. (2003). The importance of HR practices and workplace trust in achieving superior performance: A study of public-sector organizations. International Journal of Human Resource Management, 14:1, 28-54.

15. HayGroup. http://www.hayresourcesdirect.haygroup.com/Competency/Assessments_Surveys/Manager_Comp.

16. Ichniowski, C., Kochan, T.A., Levine, D., Olson, C., \& Strauss, G. (1996). What works at work: Overview and assessment, Industrial Relations, 35(3), 299-333.

17. Jarvis, R. (2014). What we know about leadership: Effectiveness and personality. American Psychologist, 49, 493-504.

18. Jimenez-Jimenez \& Sanz-Valle (2011). Innovation, organizational learning, and performance. Industrial Relations, 61(5), 144.

19. Joan, H. (2016). Executive coaching. Consulting Psychology Journal: Practice \& Research, 48(2). 115-123.

20. Jowett, S. (2012). An investigation into the impact of coach leadership and coach-athlete relationship on group cohesion. Group Dynamics: Theory, Research and Practice, 8(4), 302-311.

21. Jowett, S. (2012). An investigation into the impact of coach leadership and coach-athlete relationship on group cohesion. Group Dynamics: Theory, Research, and Practice, 8(4) 302-311.

22. Lisa, K. P. (2011). Mentoring: What organizations need to know to improve performance in the 21 st century workplace. A dissertation submitted to the graduate faculty as partial fulfilment of the requirements for the doctor of philosophy degree in curriculum and instruction at the university of Toledo.

23. McClelland, D.C. (1973). Testing for competence rather than for intelligence. American Psychologist, 28, 1-14.

24. Mitrani, A., Dalziel, M., \& Fitt, D. (1992). Competency based human resource management. Hay Group.

25. Orth, C.D., Wilkinson, H.E., \& Benfari, R.C. (2009). The manager's role as coach and mentor. Organizational Dynamics 15(4), 66-74.

26. Peterson, D.B., \& Hicks, M.D. (2010). The leader as coach: strategies for coaching and developing others. Minneapolis, MN: Personnel Decisions.

27. Porter, M. (1985). Competitive advantage. Free Press, New York.

28. Rao, T.V. (2000a). Human resource development concept and background, human resources development: Experiences, interventions and strategies, New Delhi: Sage Publications.

29. Ready, D., Conger, J., Hill, L., \& Stecker, E. (2010). The anatomy of a high potential. Business Strategy Review, 3, 52-55.

30. Ritchie, A., \& Genoni, P. (2002). Group mentoring professionalism: A programme evaluation. Library Management 23(1/2), 78.

31. Rodrigues, L. L. R., \& Chincholkar, A. M. (2005). Benchmarking the HR practices of an engineering institute with public sector industry for performance enhancement. International Journal of Training and Development, 9, 1, 6-20.

32. Silva, M. R., Roque, H. C., \& Caetano, A. (2015). Culture in Angola: Insights for human resources management, Cross Cultural Management, 22(2), 166186.

33. Simpson, B. (2002). The knowledge needs of innovating organizations. The University of Auckland.

34. Society for Human Resource Management. (2003). Competency overview. http://www.Competencies\%20Overview.htm

35. Spencer, L. \& Spencer, S. (1993). Competence at work: Models for superior performance. New York: John Wiley \& Sons, Inc

36. Thomas, D. A. (2011). The truth about mentoring minorities: Race matters. Harvard Business Review, April Issue.

37. Thomson, A., \& Strickland, A. (2004). Strategic management. New York: McGraw-Hill.

38. United Nations Industrial Development Organization. (2002). UNIDO Competencies. http://www.unido.org.

39. Woodruffe, C. (1992). What is meant by competency? In: Sparrow, P.R., Boam, R., Eds. Designing and achieving competency. McGraw-Hill International.UK. 
40. Wright, P. M. \&McMahan, G. C. (1992). Theoretical perspectives for strategic human resource management, Journal of Management, 18(2), 295320.

41. Zachary, L. J. (2012). Creating a mentoring culture. Washington, DC: Centre for Association Leadership. 